\section{Homogeneous Catalytic Activation of Hydrogen in Aqueous Solutions of Cobaltous Cyanide and Ethylenediamine}

ONE of the most active systems for the homogeneous activation of molecular hydrogen is an aqueous solution of potassium pentacyanocobaltate-(II), because of the high rate with which it absorbs $\mathrm{H}_{2}$. In the presence of deuterium this system also catalyses the exchange reaction $\mathrm{D}_{2}-\mathrm{H}_{2} \mathrm{O}$, but with a considorably lower rate than that of the hydrogen absorption. The mechanism of the multiple reactions which take place in these solutions has been recently elucidated ${ }^{1-5}$.

The reaction product between pentacyanocobaltate-(II) and hydrogen is the relative stable hydrido-complex $\left(\mathrm{Co}(\mathrm{CN})_{5} \mathrm{H}\right)^{3-}$ which forms an intermediate step in the exchange reaction. This stability, which is caused by the strong ligand field of the cyano complex, determines the rato of the isotopic exchange, because of the relatively slow rebuilding rate of hydrogen and $\left.(\mathrm{Co} / \mathrm{CN})_{5}\right)^{3-}$.

In en attempt to increase the rate of the exchange reaction and thus the catalytic activity of this system, we have partially substituted the cyano-ligands with ethylenediamine, obtaining much less stable hydrido-complexes. The precipitate of $\mathrm{Co}(\mathrm{CN})_{2}$ is redissolved at a $\mathrm{CN} / \mathrm{Co}$ ratio of $\geqslant 5$, resulting in green solutions. In the presence of ethylenediamine $(E n)$, however, the cobaltous cyanide is dissolvod at $\mathrm{CN} / \mathrm{Co}$ ratios $<5$ resulting in solutions the colours of which change from orange to yellow and green, as a function of the ratio $\mathrm{Co} / \mathrm{CN} / \mathrm{En}$. These systems are unstable and liberate $\mathrm{H}_{2}$ at about $30^{\circ} \mathrm{C}$. To increase their stability and to pormit us to measure the kinetics of isotopic exchange, wo have worked at high hydrogen pressures, with a technique described in a previous paper ${ }^{5}$. The rates of the exchange reaction:

$$
\mathrm{H}_{2}+\mathrm{HDO} \rightleftharpoons \mathrm{HD}+\mathrm{H}_{2} \mathrm{O}
$$

and the activation energies were determined in the temperature range $30^{\circ}-70^{\circ} \mathrm{C}$ for different $\mathrm{Co} / \mathrm{CN} / E n$ ratios. The concentration in Co was maintained at $0 \cdot 16$ mole/l. Table 1 contains the results obtained at three different hydrogen pressures, at $30^{\circ} \mathrm{C}$ and at a high stirring rate, so that transport processes do not interfere with the exchange processes. The HD concentrations were measured by gas chromatography and the exchange rate constants $k$ evaluated from equation ${ }^{5}$ :

$$
k=\frac{h}{(\alpha+h / H) \cdot V \cdot t} \cdot \ln \frac{n(\infty)-n(0)}{n(\infty)-n(t)} \text { mole/ml.sec }
$$

where $\alpha$ represents the equilibrium constant of reaction (1), $h$ and $H$ the amounts (moles) of hydrogen and water utilized, $V$ the volume (ml.) of the solution, $n(\infty), n(0)$ and $n(t)$ the $\mathrm{D}$-concentrations in the gas phase at equilibrium, at the initial time and the moment $t$ (sec) respectively.

Table 1. Exchange Rates and Activation Energies

Co: CN : En
ratio
(moles)
$1: 1: 3$
$1: 2: 3$
$1: 3: 3$
$1: 4: 3$
$1: 553$
$1: 6: 3$
$1: 6: 0$

$\begin{array}{cc} & k .10^{7}\left(\mathrm{~mol} . \mathrm{ml} .^{-1} \mathrm{sec}^{-1}\right) \\ 10 \mathrm{~atm} . & 30 \mathrm{~atm} . \\ 0.96 & 1 \cdot 7 \\ 2 \cdot 3 & 4 \cdot 5 \\ 2 \cdot 4 & 6 \cdot 2 \\ 2 \cdot 7 & 6 \cdot 0 \\ 1.4 & 3 \cdot 5 \\ 0.15 & 0 \cdot 16 \\ 0.16 & 0 \cdot 16\end{array}$

$60 \mathrm{~atm}$
$2 \cdot 0$
$6 \cdot 2$
$9 \cdot 7$
$10 \cdot 0$
$4 \cdot 9$
$0 \cdot 16$
$0 \cdot 16$

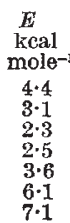

The solution with a Co/CN/En ratio between $1: 3: 3$ $1: 4: 3$ givos the highest activity. This system is the most active for the homogeneous catalysis of hydrogenwater exchange and has the lowest activation energy so far reported. In comparison to the pentacyanocobaltate(II) with a pressure-indepondent exchange rate, in our cyano-ethylene-diaminecobaltate-systems with a Co/CN/ En ratio of $1: 3: 3-1: 4: 3$ the rate increases nearly proportionally with the $\mathrm{H}_{2}$-prossure. In this system the rate-determining step in the exchange is not the decomposition of the hydride, which is very unstable now, but the formation of the hydride.

Detailed information about the mechanisms of the reactions and the complex species $\left(\mathrm{Co}(\mathrm{CN})_{x}(E n)_{y}\right)$ predominant in these systems and their hydrides, will be given in another paper. In this work we have attempted to show that to obtain an active catalyst it is important that both hydride formation and hydride decomposition occur at a similar rate, that is, within the same order of magnitude.

Otto Piringer

Alexandru Farcas

Institute for Atomic Physics, Cluj, Rumania.

1 Mills, G. A., Weller, S., and Wheeler, A., J. Phys, Chem., 63, 403 (1959). ${ }^{2}$ Griffth, W. P., and Wilkinson, G., J. Chem. Soc., 2757 (1959).

${ }^{3}$ King, N. K., and Winfield, M. E., J. Amer. Chem. Soc., 83, 3366 (1961). "Schindewolf, U., Ber. Bunsenges. Physik. Chem., 67, 219 (1963).

${ }_{5}^{5}$ Piringer, 0., paper read at the third meeting for Stable Isotopes, Leipzig (1963).

\section{Two-photon Ionization of 3,4-Benzpyrene in Boric Acid Glass}

A STUDY of the photoionization of 3,4-benzpyrene in boric acid glass has shown that two-photon ionization occurs in this system. The glass was prepared in the usual way ${ }^{1}$, formed into a strip and placed in the focal plane of a quartz spectrograph. The glass was irradiated with light from a high-pressure mercury lamp for periods of several hours. The variation of ionization density with exciting wave-length was determined by measuring the optical absorption in a region where the ion alone absorbs $\left(\approx 18,000 \mathrm{~cm}^{-1}\right.$ (ref. 2)) and correcting for the intensity distribution of the exciting light ${ }^{3}$. The expected short-wave-length region of ionization was found with a low-energy cut off of $4.9 \mathrm{eV}$, together with a second region of considerably lower density extending from $4 \cdot 1$ to $3 \cdot 0 \mathrm{eV}$. In the region $4 \cdot 9-4 \cdot 1 \mathrm{eV}$ the density was too low to be measured and corresponds to a region of low exciting intensity.

The variation of ionization density with exciting light intensity $I$ was determined by reducing $I$ by factors of $1 \cdot 8,2 \cdot 2$ and $2 \cdot 5$. It was not possible to operate over $a$ larger range without requiring excessive irradiation times. Within these limits the normal region density was proportional to $I$ while in the lower energy region it varied as $I^{2}$, thus indicating a two-photon process in the latter region. This requires some intermediate state of long life-time, which could be a triplet state or an excited state of some complex between the hydrocarbon and the boric acid glass ${ }^{4,5}$. In the present case, the difference between the two ionization cut-off potentials is $4 \cdot 9-3 \cdot 0=1.9 \mathrm{eV}$, while the triplet energy-level is at $1.8 \mathrm{eV}$ (ref. 6). This agreement is close enough to indicate that the intermediate state is the triplet state.

This conclusion agrees with that of Joussot-Dubien and Lesclaux $^{7}$, who examined the rate of ionization as a function of triplet life-time, with particular reference to triphenylene which has a long life-time $(\approx 15 \mathrm{sec})$ and a high phosphorescence efficiency. In contrast, 3,4-benzpyrene has a short life-time $(<0.1 \mathrm{sec})$ and only a weak phosphorescence. Repeating the present experiments with triphenylene has shown that the ionization density in the low-energy band varies linearly with $I$ rather than as $I^{2}$, but this is probably a consequence of the relative ease of obtaining 100 per cent population of the triplet state in this case ${ }^{7}$. Tonization was found for energies down to the long wave-length cut-off of the absorption spectrum $(3.38 \mathrm{eV})$, the first singlet state peak being at $3.54 \mathrm{eV}$ and the triplet level at $2 \cdot 88 \mathrm{eV}$ (ref. 8). The ionization potential in the glass is not known; but if the free molecule value is reduced by the same amount as in the case 